\title{
Survey of Antagonistic Action and the Mechanism of these Actions that Terpens, Phenols and their Derivatives Possess Against Different Pathogenic Agents
}

\author{
Ali Muayyed Najem \\ Biology Department, College of Science, Baghdad University, Baghdad-Iraq
}

\begin{tabular}{ll}
\hline \multicolumn{1}{c}{ Article's Information } & \multicolumn{1}{c}{ Abstract } \\
\hline Received: & $\begin{array}{c}\text { Folk medicine or herbal treatment has been used for centuries by different } \\
\text { ancient civilizations against various ailment agents, herbal medicine has been }\end{array}$ \\
Accepted: & dragged attention by researchers in different medical branches focusing on \\
28.08 .2021 & therapeutically characteristic features of each plant against different pathogenic \\
Published: & agents responsible for most devastating and terrifying diseases, in addition to \\
$31-12-2021$ & thorough investigation for the phytochemical compounds in each plant \\
Keywords: & responsible for its potent against pathogens. Thus, this study highlights on two \\
Terpenes & major groups of secondary metabolic compounds: terpens, phenols and their \\
Phenols & derivatives as antimicrobial agents against different bacterial and fungal strains \\
Mechanisms of action & especially drug resistant bacteria which responsible for the infectivity of \\
Antagonistic activity & treatments of most infectious diseases. Furthermore, mechanisms of actions of \\
& these secondary metabolites are reviewed as the causative factors responsible for \\
& the antimicrobial activity of plants and the promising results which have been \\
& achieved in multiply these activities by making combination between these \\
& natural products and chemical drugs.
\end{tabular}

DOI: 10.22401/ANJS.24.4.09

*Corresponding author: alimuayyedllll@gmail.com

\section{Introduction}

The grand achievement in medicine was overcoming pathogens life threating by discovering the penicillin and that was the dawn of a new era of fighting back the causes of unseen enemy responsible for catastrophic deceases along the history of mankind, despite this triumph over decades pathogens had been developed different types of mechanisms against drugs which have become life threating dilemma making large pharmaceutical companies in great risk of losing the race against unstopping and rapid drug resistant pathogens development [1]. Many resistance means had been developed by bacteria against antibiotics: (1) changing of antibiotic protein target, (2) degrading the antibiotics by production different enzymes for such purpose, (3) modification in permeability of cell wall, (4) expelling of drug by using pump system [2,3]. Folk medicine have been used worldwide by vast majority of people with health problems in aid of traditional healers whom used herbal treatment with effective results against different diseases, thus plant extracts have been suggested by many researchers to treat many diseases and overcome defense or resistance mechanisms pathogens have been developed against drugs or using a combination between natural extract from plants and chemical drugs [4]. Some of these phytochemicals are used by plants as defense means against herbivorous or invaders [5]. Terpenes and phenols in addition to their derivatives are the most common effective antimicrobial and mechanisms of action of these phytochemicals against pathogens will be overviewed.

\section{Terpenes and Their Derivatives}

Terpenes are polymers of single monomer called isoprene unit (C5H8), these hydrocarbon compounds are synthesized by certain pathways: Methylerythritol Phosphate (MEP) and the mevalonate pathway from Acetyl CoA precursor. Terpens differ in numbers and most common terpens are monoterpenes and sesquiterpenes while diterpenes and triterpenes are less commonly found [6]. P-Cymene, limonene, carene, and pinene are examples of terpene compounds while linalool, menthol, carvacrol, thymol, and geraniol are examples of terpenoids, modification of functional group of terpens results in many derivatives called terpenoids, therefore the bioactivity of terpenoids against pathogens differs according to distinctions in their functional group [7].

\subsection{Antimicrobial activity of Terpenes and Terpenoids}

Vast group of terpenoids have been discovered more than 40,000 varieties, these phytochemicals exhibit encouraging antimicrobial potentiality [8]. The enormous numbers of terpenoid varieties depending on distinctions in numbers of isoprene units were sub grouped into eight major classes: (sesterpenoids, monoterpenoids, sesquiterpenoids, 


\section{Al-Nahrain Journal of Science}

ANJS, Vol.24 (4), December, 2021, pp. 59-67

diterpenoids, tetrapenoids, triterpenoids, hemiterpenoids, and polyterpenoids) [9]. Griffin et al. [7] studied role of most terpenoids in the inhibition of two metabolic pathways in microbes responsible for their survive includes: oxygen uptake and oxidative phosphorylation. Oxygen is required for energy production for growth of aerobic microbes and reducing in oxygen concentrations causes reducing of respiration rate leads to limitation in bacterial growth rates [10]. Oxidative phosphorylation in the microbe could be inhibited due to terpene interaction causes alteration in cellular respiration [11]. Carbonylation of terpenoids causes exponentially elevation in bacteriostatic activity and the distinction between bacteriostatic and bactericidal activity could be summarized as the bacteriostatic agent causes limitation or stopping of microbial growth, meanwhile bactericidal causes elimination of microbes. Due to their solubility in water terpenoids showed highly antiseptic property. Hydroxyl group of terpene and its lipophilicity are two important factors responsible for its antibacterial activity [11]. Treatment of skin infection, studies showed that terpenes effects the lipodial intermembrane and polar transmembrane pathways by affecting on both lipophilic tails and polar head groups of intermembrane lipid [12].

\subsection{Monoterpenes and their derivatives}

Monoterpenes consist from two isoprenes and reported by [7] that these compounds exhibit inhibitory effects against both Gram-positive and Gram-negative bacteria, carvacrol, thymol, menthol, and geraniol are examples for monoterpenes. [13] Reported that geraniol increased susceptibility of the Gram-negative multi-drug resistant (MDR) Enterobacter aerogenes by becoming a potent efflux pump inhibitor.[14] studied inhibitory effect of three monoterpenes thymol, menthol and linalyl acetate against $S$. aureus and E. coli. Cytotoxicity, antialgal and antimalarial are promising inhibitory characteristics possess by halogenated monoterpenes, while monocyclic monoterpenes showed insecticidal and antifungal effects [15].

Early 1979, [16] studied 13 monoterpenes for their antifungal activity which exhibited inhibitory effect against 14 fungi and these mnoterpenes included in the study were: $\alpha$-pinene, $(+)$ - $\beta$-pinene, $(+)$-limonene, $\rho$-cymene, $( \pm)$ linalool, $\beta$-myrcene, terpinene, $\alpha$-phellandrene, terpinolene, $((+)$-terpinen-4-ol, $\quad \gamma$-terpinene, 1,8-cineole, $\alpha$-terpinoel. Other monoterpenes compounds (thymol, carvacrol and eugenol) were exhibited highly antibacterial activity [17]. Another twenty one monoterpenes (thymol, d-3-carene, (-)thujone,carvacrol methyl ester, cis/trans citral, eugenol, $\alpha-$ pinene geraniol, Geranyl acetate, cis-hex-3-en-1-ol, $\alpha$ terpinene, (2)-linalool, menthone, nerol, $\mathrm{R}(+)$ limonene, $\beta$ pinene, (+)sabinene, terpinen-4-ol, $\alpha$-terpineole, carvacrol, borneol) these compounds were highly active against 25 bacterial strains [18]. carvacrol were reported to inhibit biofilm development of S.aureus and S. typhimurium [19]. [20] found that monoterpenes linalool from essential oil extracted from lavender showed significant antibacterial activity against $K$. pneumoniae, and the mechanism of action of linalool against the bacteria was membrane distruption.

Antimicrobial properties were found that monoterpene ketones exhibited [21]. However, alcoholic monoterpenes showed bactericidal activity rather than bacteriostatic activity. [21] studied that alcoholic monoterpenes: linalool, $\alpha$-terpineol, terpinen-4-ol, and 1, 8-cineole showed significant fungicidal activity and "suggested alcohol moieties as determinants of antifungal activity". According to negative responses myrcene (acyclic monoterpenes) showed against certain fungi, deducing from this result that cyclic monoterpenes could be responsible for such activity [22]. Antimicrobial activity of monoterpenes aldehydes could be explained due to its carbon double bonds which create strong electronegativity. In 1989 Thompson tested antiviral potentiality of nine monoterpenes $(1,8$-cineole, $\gamma$ terpinene, citral, $\rho$-cymene, terpinen-4-ol, $\alpha$-terpineol, $\alpha$ terpinene, $\alpha$-pinene and $\alpha$-terpinene) against Herpes simplex virus type 1 ( $\mathrm{HSV}-1)$ and revealed a significant positive response against the virus, [23] experimented effect of 1,8-cineole, thujone, camphor, borneol, bornyl acetate, and isoborneol against HSV-1 which came out with significant antiviral potent. In addition to considerable antiviral activity of the pre mentioned monoterpenes thymol and carvacrol showed remarkable activity against Cucumber mosaic virus (CMV) and Tobacco mosaic virus (TMV) [24].

\subsection{Sesquiterpenes and their derivatives}

Sesquiterpenes is comprised from three isoprene units, antiinflammatory activity of sesquiterpene lactones especially those containing an alpha-methylene-gamma-lactone moiety revealed an inhibitory potentiality of chronic adjuvant-induced arthritis and carrageenan-induced edema in rodents, the mode of their action could be explained by their impact on human polymorphonuclear neutrophils by uncoupling oxidative phosphorylation, in addition to increase cyclic adenosine monophosphate levels of rat neutrophils and inhibition of the activity of lysosomal enzymes in both rat and mouse liver [25]. $9 \beta$-dibenzoyloxydihydro- $\beta$-agarofuran had been recorded for its inhibitory activity against Bacillus spp. [26] acyclic sesquiterpene (farnesol) revealed moderate anti biofilm activity against Streptococcus sobrinus and Streptococcus mutans, [27]. Furthermore farnesol showed antibacterial and antibiofilm effect against $S$. epidermidis and S. aureus [28]. Without any change in the microbial flora a combination of farnesol and xylitol showed significant impact against atopic dermatitis caused by $S$. aureus, in addition to the combination inhibitory effect against $S$. aureus biofilm production [29]. Another combination of farnesol with doxycycline, sulfamethoxazole-trimethoprim, amoxicillin and ceftazidime showed inhibitory effect against $B$. pseudomallei [30]. Results revealed that xanthorrhizol reduced most of the adherence ability of Staphylococcus mutans cell [31], also inhibited Mycobacterium smegmatis 


\section{Al-Nahrain Journal of Science}

ANJS, Vol.24 (4), December, 2021, pp. 59-67

growth [32]. Incorporation of sesquiterpenes into antibiotics have been shown enhancement in the antibiotic activity against MRSA and Gram-negative bacteria [33]. Another combination between sesquiterpenes and a set of antibiotics: erythromycin, vancomycin, penicillin and tetracycline reported increasing in the inhibition zone against MDR strains of $S$. aureus [34].

\subsection{Diterpenes and their derivatives}

Diterpene is comprised from four isoprene units and responsible for many bioactivities such as plant growth and development since gibberellic acid (GA3) is a tetracyclic diterpene [35]. Minimum inhibitory concentration (MIC) of 60 terpenoids have been experimented against $S$. aureus, $P$. aeruginosa, C. albicans and E. coli, mechanism of action of those terpenoids were determined after sub grouped into five groups, low solubility in water seemed to be the reason of their antimicrobial inactivity while hydrogen bond was responsible for the positive antimicrobial potentiality [36]. Furthermore, [36] suggested that inhibition of oxygen uptake and oxidative phosphorylation as main fundamental bioactive processes to sustain energy production in microbial cells was the reason behind the bioactivity or the antimicrobial activity of diterpenes. [37] reported significant antimicrobial activities of two diterpenes derivatives (ent-pimarane and ent-kaurane) against dental caries pathogens. However, the diterpenoid salvipisone reported that this compound possessed antibiofilm potent and prevented adherence of $S$. aureus and $S$. epidermidis cells [38].

In addition to sesquiterpenes, significant results have been optimistically revealed that incorporation of diterpenes into antibiotics enhanced the antibacterial activity against drug-resistant bacteria (MRSA), for instance, an enhancement in the antibacterial activity of several antibiotics such as linezolid, daptomycin, oxacillin and tetracycline against MRSA after a combination with clerodane diterpenoid 16ahydroxycleroda-3, 13 (14)-Zdien-15, 16-olide (CD) extracted from leaves of Polyathia longifolia [39]. Moreover, [39] was also tested the same MRSA isolates against CD combined with another antibiotics such as: ofloxacin, norfloxacin and ciprofloxacin and against CD apart, the results showed highly antibacterial activity represented by reversing resistance of MRSA isolates and the mechanism of action in vivo could be explained that genes expression coding for efflux pumps were remarkably modulated in MRSA cells treated with CD alone and in combination with antibiotics bacterial cells depending on the qRT-PCR analysis. Results of time-kill assay recorded that the $\mathrm{MIC}$ of $\mathrm{CD}$ and norfloxacin combination was half of the MIC of CD and norfloxacin apart, undoubtedly such promising outcomes will increase the scientific interest for further experiments to pave the way to overcome the rapidly drug resistance development but this breakthrough results offered by $\mathrm{CD}$ became a bottleneck because of sourcing to obtain CD [40].
Diterpenoids salvipisone and aethiopinone extracted from Salvia sclarea root was test against S. epidermidis, Enterococcus faecalis and $S$. aureus for their antibacterial and antibiofilm activity revealed positive effect against the bacterial strains, in addition to pre mentioned test another experiment was conducted to assess the synergistic effect of a combination from the two diterpenoids (salvipisone and aethiopinone) with antibiotics included oxacillin, vancomycin, and linezolid, the antimicrobial impact of the combination was tested against Methicillin resistant Staphylococcus epidermidis (MRSE) and MRSA, the combination showed either bacteriostatic or bactericidal activity against MRSA and MRSE in a remarkable result represented by reducing $50 \%$ of the antibiotics dose when diterpenoids were used in the combination [41].

\subsection{Triterpenes and their derivatives}

Triterpenes is comprised from six isoprene units. It was reported that Oleanic acid (OA) which is a triterpene with significant potentiality against Mycobacterium tuberculosis, same study recorded in the light of the results that combination between OA with ethambutol, rifampicin and isoniazide showed promising synergistic effects against multidrug-resistant bacteria (MDR) with reducing MIC from $128-16$ fold to $32-4$ fold, and from 128 to 16 fold, respectively [42].

Two triterpenoids OA and bonianic acid were extracted from Radermachera boniana. Both compounds showed antibacterial activity against $M$. tuberculosis. Furthermore, a synergism between ergosterol peroxide and ursolic acid (UA) combination between those two triterpenoids showed also positive effect against $M$. tuberculosis [43]. Another study was conducted to test the antibacterial activity of OA and UA which was isolated from Miconia ligustroides, those two triterpenoids showed bactericidal effect against (Streptococcus pneumoniae, S. choleraesuis, Vibrio cholera, B. cereus and $K$. pneumoniae), MIC value of UA against $B$. cereus was $20 \mu \mathrm{g} / \mathrm{mL}$ and OA showed MIC value of $80 \mu \mathrm{g} / \mathrm{mL}$ against $B$. cereus and $S$. pneumoniae [44]. In 2013, Another study was carried out to evaluate antibacterial and anti-biofilm of OA and UA which reported active against planktonic cariogenic microorganism [45]. In 2015, a study tested combinatory effects of UA and xylitol against Streptococcus mutans and S. sobrinus which showed antibacterial and anti-biofilm activity [46]. Moreover, without affecting toxin secretion both OA and UA showed inhibitory effect against Listeria monocytogenes and its biofilm production capacity, and affected the virulence of this bacterium [47].

A combination of OA with gentamicin and kanamycin exhibited outstanding antibacterial activity against Acinetobacter baumannii but not with other classes such as chloramphenicol, rifampicin, ampicillin, tetracycline and norfloxacin [40]. Amyrin, betulinic acid, and betulinaldehyde are triterpenoids extracted from of Callicarpa farinose bark showed significal antibacterial against to exhibit potent antimicrobial activity against 


\section{Al-Nahrain Journal of Science}

ANJS, Vol.24 (4), December, 2021, pp. 59-67

MRSA and methicillin-susceptible (MSSA) with MICs ranging from 2 to $512 \mu \mathrm{g} / \mathrm{mL}$ [48].

Mechanism of action of triterpenoids still not fully comprehended. However, phytochemicals mechanism of action has been reported that these compounds aim either permeability of bacterial cell membrane, inhibition some of bacterial virulence factors for instance: enzymes and toxins, in addition to suppressing biofilm production and bacterial cell adherence, also another mode of action include modulation of bacterial efflux pump [42]. For instance, mechanism of action of carvacrol had been reported responsible for alteration of fatty acid compositions, meanwhile other reports recorded that thymol and carvacrol caused disruption of the cytoplasmic membrane and disintegration of the outer membrane of Gram-negative bacteria [49].

\section{Phenols}

\subsection{Simple Phenols and Phenolic acids}

Simple phenols and phenolic acids structures range from a simple phenol ring with a single substitution (e.g.; cinnamic and caffeic acids) to multiple substitutions and hydroxylations. Studies referred to correlations between toxicity of phenols and the hydroxylation degree, more oxidized structure of the metabolic compound seems to possess it more inhibitory potent [50]. A study by [51] deduced that inhibiting of enzymes is the mechanism of phenols action and manifested that this mechanism is taken place when these phenolic compounds react with sulfhydryl groups on the proteins.

\subsection{Polyphenols}

Biological activity of polyphenols could be determined by the amount of the absorbed polyphenol without any chemically changes. Without absorption of polyphenols by gastrointestinal system, these compounds could have a great influence on the intestinal microbiota and resulted from that a two important consequences: (1) Modification of these compounds into their active forms, (2) alternations in the composition of the intestinal microbiota, leading to flourishing the beneficial bacteria and inhibiting pathogenic bacteria, for this reason polyphenols considered to have a major influence on the human health [52]. These secondary metabolic compounds subdivided into several bioactive groups.

\subsection{Quinones}

Quinone is comprised from an aromatic ring with two ketone substitutions. Antimicrobial activity of Quinone due to two major means: (1) their ability to prevent the effect of free radicles as antioxidants by electron donation to the free radicles and reducing their reactivity comes from their ability to donate free radicals. (2) inactivation of microbial enzymes due to their ability to interact with amino acids in proteins, therefore, mechanism of action of quinones could be summarized by attacking surface adhesion, enzymes of cell membrane and polypeptide of cell wall. Besides substrates required by the microorganisms could be detained by quinones [50].

A study was conducted to evaluate both methanolic and hexane extracts of Nigella sativa antibacterial activity against Streptococcus mitis, S. mutans and S. aureus, inhibition zone ranged between $15-30 \mathrm{~mm}$, and ranged between 0-22 $\mathrm{mm}$ for methanolic and hexane extracts respectively, the study referred the antibacterial potent of both extracts due to prescence of each of the following compounds: dithymoquinone, thymoquinone and thymohydroquinones [53]. However, another study reported antibacterial activity of Lebanese Annona squamosa $\mathrm{L}$. aqueous and methanolic extracts against $P$. aeruginosa, $S$. aureus, $S$. epidermidis, E. coli and $E$. faecalis, time kill assay of the extracts against the pre mentioned strains manifested that MIC and MBC were 50 $\mathrm{mg} / \mathrm{ml}$ and $100 \mathrm{mg} / \mathrm{ml}$ respectively [54]

\subsection{Flavonoids, Flavones and Flavonols}

Flavonoids are highly antioxidant water miscible natural secondary metabolic compounds presence vastly in different plant parts comprise from hydroxylated aromatic ring linked to $\mathrm{C} 3-\mathrm{C} 6$ unit. Flavones comprise from one aromatic ring with only one ketone substitution, flavonol results from hydroxylation of flavones. These compounds are produced in plants as defense mechanism against invaders such as microrganisms, thus their antimicrobial potentiality could be clearly deduced [50]. Also [50] concluded that the antimicrobial mechanisms of these secondary metabolic compounds due to the tendacy of these compounds to interact with extracellular and soluble proteins forming irreversible complexes in addition to bacterial cell wall.

Chloroform extraction of Phoenix dactylifera (date palm) against imipenem-resistant $P$. aeruginosa (IRP) administered strong antibacterial with MIC which was 0.05 $\mathrm{mg} / \mathrm{ml}$ and MBC was $2 \mathrm{mg} / \mathrm{ml}$. In addition to scanning by electron microscopy, the study determined the active compounds as flavonoid glycosides, including apigenin, quercetin, $1 \mathrm{hr}$. needed to eradicate biofilm produced by 12 (IRP) isolates using only $5 \%$ chloroform extract, results appeared using SEM that cell wall of $P$. aeruginosa after 30 min. of applying flavonoids started to deform and deformation of the cell wall completely occurred after $1 \mathrm{hr}$.; thus the study suggested that deformation of the cell wall by forming pores is the mechanism of action of flavonoids [55]. Two extracts of Thyme leaves (Thymus vulgaris) and myrrh exudates (Boswellia carterii) were screened for their phytochemicals which were chlorgenic, rosmarinic and caffeic acid, carnosol, and flavonoids, the two extracts were tested against Legionella pneumophila, B. cereus and $S$. aureus in addition to Aspergillus flavus and Fusarium oxysporum, time kill assay showed that MICs ranged between $2-4 \%(\mathrm{v} / \mathrm{v})$ [56].

Methanolic extraction of Olive leaves (O. europaea) and arugula seeds (Eruca sativa) were experimented against $S$. aureus and B. cereus. MICs for olive and arugula extracts 


\section{Al-Nahrain Journal of Science}

ANJS, Vol.24 (4), December, 2021, pp. 59-67

were 80 and $60 \mu \mathrm{g} / \mathrm{ml}$, respectively against $S$. aureus, 40 and $20 \mu \mathrm{g} / \mathrm{ml}$ against $B$. cereus, analysis for phytochemicals confirmed of flavonoids presence in the extracts [57].

Alcoholic extraction of Rosmarinus officinalis, Eucalyptus globulus, Lawsonia inermis, Zingiber officinale and Azadirachta indica (neem) were carried out and tested to assess antibacterial activity against $P$. aeruginosa, Shigella dysenteriae, E. coli and K. pneumoniae (Gramnegative bacteria) and Micrococcus roseus, B. subtilis and S. aureus (Gram-positive bacteria), 8-29 $\mathrm{mm}$ were the ranges of diameters of inhibition zones against Gramnegative bacteria and 5-18 $\mathrm{mm}$ were the ranges of diameters of inhibition zones against Gram-positive, phytochemical screening of these plants extracts showed presence of anthocyanins, saponins, steroids, flavonoids and tannins [58].

Several solvents were used to extract Yemeni lawsonia inermis leaves the solvents were: water, acetone, methanol, and ethanol. Phytochemical analysis showed presence of tannins, quinones and flavonoids in addition to alkaloids. Acetone extracts. The highest antibacterial activity as reported of acetone extract according to diameters of inhibition zones $36,17,30,34$, and $24 \mathrm{~mm}$ against $B$. subtilis, E. coli, Listeria monocytogenes, Kocuria rhizophila, and S. epidermidis, respectively, while aqueous extract showed merely or no antibacterial activity [59].

\subsection{Tannins}

Tannins are subdivided into two groups: condensed tannins which is more abundant and hydrolysable tannins and gallic acid considered the basis of hydrolysable tannins and this type of tannins is a polymer of flavonoids monomers and could be named proanthocyanidins [50]. polymerization and oxidation of tannins determine their biological activity [60]. Mechanism of action of tannins against pathogens could be explained due to (1) complexes they form with proteins and even polysaccharide by covalent and noncovalent interactions. (2) Evidence of binding cell walls of ruminal bacteria, inhibiting growth and protease activity, in addition to changing morphology of the germ tubes of Crinipellis perniciosa by low concentrations of tannins [50].

Antifungal activity of Conocarpus erectus crude alcoholic extract was evaluated in comparison to purified tannins, tannins showed higher potentiality against three fungal isolates: Penicillium chrysogenum, Saccharomyces cerevisiae and A. niger, while the crude extract showed activity against S. cerevisiae only [61]. Aquoeous and ethanolic extracts of Olea sp. growing in the Albaha region in Saudi Arabia were tested against: P. aeruginosa, E. coli, S. pyogenes, Salmonella sp. and S. aureus, ethanolic extract demonstrated the higher antibacterial and phytochemical screening of Olea sp. showed high concentration of tannins as well as flavonoids, steroids, terpenoids, and coumarins [62]. Zingiber officinale and Curcuma longa were extracted by methanol and water and experimented for their antibacterial activity against: $S$. aureus, $S$. pyogenes, $P$. aeruginosa and E. coli, Aqueous and methanolic extracts of Curcuma longa illustrated higher antibacterial activity than both extracts of $Z$. officinale depending on the diameters of inhibition zones, tannins is presence in the extracts of the two plants according to phytochemical screening [63]. Punica granatum peel was extracted by methanol to evaluate its antibacterial activity against: Vibrio cholera, E. coli, Salmonella spp.and Listeria monocytogenes, results showed activity against the tested strains, while phytochemical analysis indicate presence of tannins, gallic acid and ellagic acid [60]. 22 polyphenols were tested for their antibacterial activity against several strains of Grampositive and Gram-negative bacteria, some of these phenols such as pyrogallol-based compounds were more active than the others for instance resorcinol and catechol [64]. However, a direct proportion was reported between increasing of antimicrobial activity or toxicity of phenols and hydroxylation of such compounds [65]. Moreover, interaction with sulfhydryl groups in microbial enzymes responsible for the inhibition of these enzymes and that could be explained mechanism of action of simple phenols [66]. Antibacterial activity of phenolic acid (caffeic acid) was assesses against $S$. aureus and Escherichia coli in comparing to ampicillin, caffeic acid showed higher MIC than that ampicillin achieved [67]. Another study conducted to evaluate antibacterial activity of gallic acid against Campylobacter coli which demonstrated bactericidal activity with 61.5-125 $\mu \mathrm{g} / \mathrm{ml}$ MIC [68]. Furthermore, a study was carried out to compare between antibacterial activity of gallic acid and ferulic acid against $P$. aeruginosa, E. coli, S. aureus and Listeria monocytogenes, depending on MIC readings ferulic acid was more potent against the bacterial strains than gallic acid, this study also reported that "Gallic acid and ferulic acid affect the bacterial cell wall of $S$. aureus, E. coli, and P. aeruginosa, producing local damage and leakage of cellular materials" [69]. Potentilla fruticosa extract was analyzed for its phytochemical contents and it was found rich in ferulic acid, ellagic acid, hyperoside, (+)-catechin, caffeic acid and rutin, the extract showed highest antimicrobial activity against Gramnegative bacterium $P$. aeruginosa, and a yeast Candida albicans [70]. [71] studied synergistic effect of polyphenols in a Cistus salviifolius extract, a combination of flavonoids and ellagitannins in certain ratio showed positive effect against S.aureus. Another study showed that inhibitory effect of synergism between isoquercitrin and gallic acid was 10-fold higher than their effect apart [72].

Extract of Mangifera indica seeds was active against MRSA, the extract analyzed for its phytochemicals which appeared containing: pentagalloylglucopyranose, gallic acid and methyl gallate [73]. Antibacterial activity of several phenolic compounds against $S$. aureus was assayed and MICs was $21 \mu \mathrm{g} / \mathrm{ml}$ of octyl gallate, $103 \mu \mathrm{g} / \mathrm{ml}$ of hydroquinone and $413 \mu \mathrm{g} / \mathrm{ml}$ of both carvacrol and thymol [74]. 


\section{Al-Nahrain Journal of Science}

ANJS, Vol.24 (4), December, 2021, pp. 59-67

\subsection{Polyphenols mechanism of action}

Various mode of actions are considered responsible for inhibitory effect of polyphenols against pathogens, inhibition of microbial enzymes by oxidized compounds is among these modes either by interaction with sulfide functional group of proteins or through nonspecific proteins [75]. A quite contradiction has been established about whether polyphenol with a hydroxyl group is more toxic or more active against pathogens or not, [76] reported that highly oxidized polyphenols are more active against microbes than less oxidized, while [77] showed that flavonoids without hydroxyl group at their $\beta$-rings are more affective against microbes by causing more membrane disruption. In addition to the pre mentioned means of actions, some phenolic compounds as quinones act as stable free radicles bind with microbial proteins irreversibly causing lose their functions, or inactivating enzymatic activity by different means either by binding to cell wall proteins and interacting with substrates make them unavailable to the microbes or making complexes with metal irons [50].

\section{Conclusion}

Secondary metabolic compounds produced by all plants including terpens and phenols play various roles in persistence of plants mostly as defense mechanisms against predators, however different ancient civilizations, even modern cultures and ethnics depend thoroughly in their therapeutical strategies on traditional or herbal remedies, during last century till day many studies had been conducted to magnify the essence role of terpens, phenols and their derivatives in various medical, biotechnical and industrial lines in order to cope the accelerating challenges confront the humanity.

\section{References}

[1] Oluwatuyi M.; Kaatz G.W.; and Gibbons S.; "Antibacterial and resistance modifying activity of Rosmarinus officinalis", Phytochemistry, 65: 3249-54, 2004.

[2] Blair J. M.; Webber M. A.; Baylay A. J.; Ogbolu D. O.; and Piddock L. J.; "Molecular mechanisms of antibiotic resistance", Nat Rev Microbiol, 13: 42-51, 2015.

[3] Abreu A. C.; McBain A. J.; and Simões M.; "Plants as sources of new antimicrobials and resistance-modifying agents", Nat Prod Rep.; 29: 1007-21, 2012.

[4] Chlez Z.; Hohmann J.; and Molnar J.; "A source of complementary therapeutics. In: Chattopadhyay D, editor. Ethnomedicine. $1^{\text {st }}$ ed. India: Research Signpost", 179-201, 2010.

[5] Simões M.; Bennett R. N.; and Rosa E. A.; "Understanding antimicrobial activities of phytochemicals against multidrug resistant bacteria and biofilms", Nat Prod Rep.; 26: 746-57, 2009.

[6] Swamy, M. K.; Akhtar M. S.; and Sinniah U. R.; "Antimicrobial properties of plant essential oils against human pathogens and their mode of action: An updated review. Evid.-Based Complement", Altern. Med.; doi: 10.1155/2016/3012462, 2016.

[7] Griffin S. G.; Wyllie S. G.; Markham J. L.; and Leach D. N.; "The role of structure and molecular properties of terpenoids in determining their antimicrobial activity", Flavour Fragr. J.; 14: 322-332, doi: 10.1002/(SICI) 1099, 1999.

[8] Barbieri R.; Coppo E.; Marchese A.; and Daglia M.; Sobarzo-Sánchez E.; and Nabavi S.F.; "Phytochemicals for human disease: An update on plant-derived compounds antibacterial activity", Microbiol. Res.; 196: 44-68, doi: 10.1016/j.micres.2016.12.003, 2017.

[9] Zacchino S. A.; Butassi E.; Cordisco E.; and Svetaz L. A.; "Hybrid combinations containing natural products and antimicrobial drugs that interfere with bacterial and fungal biofilms", Phytomedicine.; 37: 14-26, doi: 10.1016/j.phymed.2017.10.021, 2017.

[10] Shaw M. K. and Ingraham J. L.; "Synthesis of macromolecules by Escherichia coli near the minimal temperature for growth", J. Bacteriol.; 1: 157-164, 1967.

[11] Zengin H.; and Baysal A.; "Antibacterial and antioxidant activity of essential oil terpenes against pathogenic and spoilage-forming bacteria and cell structure-activity relationships evaluated by SEM microscopy", Molecules. 11: 17773-17798, doi: 10.3390/molecules191117773, 2014.

[12] Chen J.; Jiang Q. D.; Chai Y. P.; Zhang H.; Peng P.; and Yang X.X.; "Natural terpenes as penetration enhancers for transdermal drug delivery", Molecules; 12, 1709, doi: 10.3390/molecules21121709, 2016.

[13] Lorenzi V.; Muselli A.; Bernardini A. F.; Berti L.; Pagès J. M.; Amaral L.; and Bolla J. L.; "Geraniol restores antibiotic activities against multidrugresistant isolates from Gram-negative species", Antimicrob. Agents Chemother; 53: 22092211, doi: 10.1128/AAC.00919-08, 2009.

[14] Trombetta D.; Castelli F.; Sarpietro M. G.; Venuti V.; Cristani M.; Daniele C.; Saija A.; Mazzanti G.; and Bisignano G.; "Mechanisms of antibacterial action of three monoterpenes", Antimicrob. Agents Chemother.; 49: 2474-2478, doi: 10.1128/AAC.49.6.24742478.2005, 2005.

[15] De Inés C.; Argandoña V. H.; Rovirosa J.; San-Martín A.; Díaz-Marrero A. R.; Cueto M.; and GonzálezColoma A.; "Cytotoxic activity of halogenated monoterpenes from Plocamium cartilagineum", Zeitschrift fur Naturforsch-Sect. C J. Biosci.; 59: 339344, doi: 10.1515/znc-2004-5-609, 2004.

[16] Kurita N.; Miyaji M.; Kuraney R.; Takahara Y.; and Ichimura K.; "Antifungal activity and molecular orbital energies of aldehyde compounds from oils of higher plants", Agric. Biol. Chem.;43: 2365-2371, 1979.

[17] Dorman H. J. D.; and Deans S. G.; "Antimicrobial agents from plants: Antibacterial activity of plant 


\section{Al-Nahrain Journal of Science}

ANJS, Vol.24 (4), December, 2021, pp. 59-67

volatile oils", J. Appl. Microbiol.; 88: 308-316, doi: 10.1046/j.1365-2672.2000.00969.x, 2000.

[18] Liu X.; Dong M.; Chen X.; Jiang M.; Lv X.; and Zhou J.; "Antimicrobial activity of an endophytic Xylaria sp. YX-28 and identification of its antimicrobial compound 7-amino-4-methylcoumarin", Appl. Microbiol. Biotechnol.; 78: 241-247, doi: 10.1007/s00253-007-1305-1, 2008.

[19] Knowles J. R.; Roller S.; Murray D. B.; and Naidu A. S.; "Antimicrobial action of carvacrol at different stages of dual-species biofilm development by Staphylococcus aureus and Salmonella enterica serovar typhimurium", Appl. Environ. Microbiol.;71: 797-803. doi: 10.1128/AEM.71.2.797803, 2005.

[20] Yang S.K.; Yusoff K.; Ajat M.; Thomas W.; Abushelaibi A.; Akseer R.; Lim S. E.; and Lai K. S.; "Disruption of KPC-producing Klebsiella pneumoniae membrane via induction of oxidative stress by cinnamon bark (Cinnamomum verum J. Presl) essential oil", PLoS ONE, 1-20, doi: 10.1371/journal.pone.0214326, 2019.

[21] Bhatti H. N.; Khan S. S.; Khan A.; Rani M.; Ahmad V. U.; and Choudhary M. I.; "Biotransformation of monoterpenoids and their antimicrobial activities", Phytomedicine; 21: 1597-1626, doi: 10.1016/j.phymed.2014.05.011, 2014.

[22] Smid E. J.; de Witte Y.; and Gorris L. G. M.; "Secondary plant metabolites as control agents of postharvest Penicillium rot on tulip bulbs.", Postharvest Biol. Technol.; 6: 303-312, doi: 10.1016/0925-5214(95)00010-4, 1995.

[23] Dunkic V.; Bezic N.; Vuko E.; and Cukrov D.; "Antiphytoviral activity of Satureja montana L. ssp. variegata (host) P. W. Ball essential oil and phenol compounds on CMV and TMV, Molecules; 15: 67136721, doi: 10.3390/molecules15106713, 2010.

[24] Astani A.; Reichling J.; and Schnitzler P.; "Comparative study on the antiviral activity of selected monoterpenes derived from essential oils", Phytother. Res.; $\quad 24: \quad 673-679, \quad$ doi: 10.1002/ptr.2955, 2010.

[25] Hall I. H.; Starnes Jr. C.O.; Lee K. H. and Waddell T.G.; "Mode of action of sesquiterpene lactones as anti-inflammatory agents", J Pharm Sci.; 69(5): 53743, doi: 10.1002/jps.2600690516, 1980.

[26] Torres-Romero D.; Jiménez I. A.; Rojas R.; Gilman R. H.; López M.; and Bazzocchi I. L.; "Dihydro- $\beta$ agarofuran sesquiterpenes isolated from Celastrus vulcanicola as potential anti-Mycobacterium tuberculosis multidrug-resistant agents", Bioorganic Med. Chem.; 19: 2182-2189, doi: 10.1016/j.bmc.2011.02.034, 2011.

[27] Koo H.; Pearson S. K.; Scott-Anne K.; Abranches J.; Cury J. A.; Rosalen P. L.; Park Y.; Marquis R. E.; and Bowen W. H.; "Effects of apigenin and tt-farnesol on glucosyltransferase activity, biofilm viability and caries development in rats", Oral Microbiol. Immunol.; 17: 337-343, doi: 10.1034/j.1399302X.2002.170602.x, 2002.

[28] Gomes F. I. A.; Teixeira P.; Azeredo J.; and Oliveira R.; "Effect of farnesol on planktonic and biofilm cells of Staphylococcus epidermidis", Curr. Microbiol. 59: 118-122, doi: 10.1007/s00284-009-9408-9, 2009.

[29] Masako K.; Yusuke K.; Hideyuki I.; Atsuko M.; Yoshiki M.; Kayoko M.; and Makoto K.; "Corrigendum to "A novel method to control the balance of skin microflora. Part 2. A study to assess the effect of a cream containing farnesol and xylitol on atopic dry skin", J. Dermatol. Sci.; 39, 197, doi: 10.1016/j.jdermsci.2005.08.003, 2005.

[30] Castelo-Branco D. S. C. M.; Riello G. B.; Vasconcelos D. C.; Guedes G. M. M.; Serpa R.; Bandeira T. J. P. G.; Monteiro A. J.; Cordeiro R. A.; Rocha M. F.; and Sidrim J. J.; et al.; "Farnesol increases the susceptibility of Burkholderia pseudomallei biofilm to antimicrobials used to treat melioidosis", J. Appl. Microbiol.; 120: 600-606, doi: 10.1111/jam.13027, 2016.

[31] Rukayadi Y.; and Hwang J. K.; "Effect of coating the wells of a polystyrene microtiter plate with xanthorrhizol on the biofilm formation of Streptococcus mutans", J. Basic Microbiol.; 46: 410415, doi: 10.1002/jobm.200510088, 2006.

[32] Jin J.; Guo N.; Zhang J.; Ding Y.; Tang X.; Liang J.; Li L.; Deng X.; and Yu L.; "The synergy of honokiol and fluconazole against clinical isolates of azoleresistant Candida albicans", Lett. Appl. Microbiol.;51: 351-357, doi: 10.1111/j.1472-765X.2010.02900.x, 2010.

[33] Zacchino S. A.; Butassi E.; Cordisco E.; Svetaz L. A.; "Hybrid combinations containing natural products and antimicrobial drugs that interfere with bacterial and fungal biofilms", Phytomedicine, 37: 14-26, doi: 10.1016/j.phymed.2017.10.021, 2017.

[34] Gonçalves O.; Pereira R.; Gonçalves F.; Mendo S.; Coimbra M. A.; and Rocha S. M.; "Evaluation of the mutagenicity of sesquiterpenic compounds and their influence on the susceptibility towards antibiotics of two clinically relevant bacterial strains", Mutat. Res. Genet. Toxicol. Environ. Mutagen, 723: 18-25, doi: 10.1016/j.mrgentox.2011.03.010, 2011.

[35] Ambrosio S. R.; Tirapelli C. R.; da Costa F. B.; and de Oliveira A. M.; "Kaurane and pimarane-type diterpenes from the Viguiera species inhibit vascular smooth muscle contractility", Life Sci.; 79: 925-933, doi: 10.1016/j.lfs.2006.05.015, 2006.

[36] Griffin S. G.; Wyllie S. G.; Markham J. L.; and Leach D. N.; "The role of structure and molecular properties of terpenoids in determining their antimicrobial activity", Flavour Fragr. J.; 14: 322-332, doi: 10.1002/(SICI) 1099-1026(199909/10)14:5<322:AIDFFJ837>3.0.CO;2-4, 1999. 


\section{Al-Nahrain Journal of Science}

ANJS, Vol.24 (4), December, 2021, pp. 59-67

[37] Souza A. B.; Martins C. H. G.; Souza M. G. M.; Furtado N. A. J. C.; Heleno V. C. G.; De Sousa J. P. B.; Rocha E. M.; Bastos J. K.; Cunha W. R.; and Veneziani R. C.; et al.; "Antimicrobial activity of terpenoids from Copaifera langsdorffii Desf. against cariogenic bacteria", Phythother. Res.; 25: 215-220, doi: 10.1002/ptr.3244, 2011.

[38] Różalski M.; Walencka E.; Różalska B.; and Wysokińska H.; "Antimicrobial activity of diterpenoids from hairy roots of Salvia sclarea L.: Salvipisone as a potential anti-biofilm agent active against antibiotic resistant Staphylococci", Phytomedicine.; 14: 31-35, 2007.

[39] Gupta V. K.; Tiwari N.; Gupta P.; Verma S.; Pal A.; Srivastava S. K.; and Darokar M. P.; "A clerodane diterpene from Polyalthia longifolia as a modifying agent of the resistance of methicillin resistant Staphylococcus aureus", Phytomedicine, 23: 654-661, doi: 10.1016/j.phymed.2016.03.001, 2016.

[40] Zacchino S. A.; Butassi E.; Cordisco E.; and Svetaz L. A.; "Hybrid combinations containing natural products and antimicrobial drugs that interfere with bacterial and fungal biofilms", Phytomedicine. 37: 14-26, doi: 10.1016/j.phymed.2017.10.021, 2017.

[41] Walencka E.; Rozalska S.; Wysokinska H.; Rozalski M.; Kuzma L.; Rozalska B.; "Salvipisone and aethiopinone from Salvia sclarea hairy roots modulate staphylococcal antibiotic resistance and express antibiofilm activity", Planta Med.; 73: 545-551, doi: 10.1055/s-2007-967179, 2007.

[42] Barbieri R.; Coppo E.; Marchese A.; Daglia M.; Sobarzo-Sánchez E.; Nabavi S. F.; "Phytochemicals for human disease: An update on plant-derived compounds antibacterial activity", Microbiol. Res.; 196: 44-68, doi: 10.1016/j.micres.2016.12.003, 2017.

[43] Jiménez-Arellanes A.; Luna-Herrera J.; CornejoGarrido J.; López-García S.; Castro-Mussot M.E.; Meckes-Fischer M.; Mata-Espinosa D.; Marquina B.; Torres J.; Hernández-Pando R.; "Ursolic and oleanolic acids as antimicrobial and immunomodulatory compounds for tuberculosis treatment. BMC Complement", Altern. Med.; 13, 258, doi: 10.1186/1472-6882-13-258, 2013.

[44] Cunha W. R.; De Matos G. X.; Souza M. G. M.; Tozatti M. G.; Andrade E.; Silva M. L.; Martins C. H. G.; Silva R. D.; Da Silva Filho A.A.; "Evaluation of the antibacterial activity of the methylene chloride extract of Miconia ligustroides, isolated triterpene acids, and ursolic acid derivatives", Pharm. Biol.; 48: 166-169, doi: 10.3109/13880200903062648, 2010.

[45] Zhou L.; Ding Y.; Chen W.; Zhang P.; Chen Y.; Lv $\mathrm{X}$.; "The in vitro study of ursolic acid and oleanolic acid inhibiting cariogenic microorganisms as well as biofilm", Oral Dis.; 19: 494-500, doi: 10.1111/odi.12031, 2013.

[46] Liu Q.; Niu H.; Zhang W.; Mu H.; Sun C.; Duan J.; "Synergy among thymol, eugenol, berberine, cinnamaldehyde and streptomycin against planktonic and biofilm-associated food-borne pathogens", Lett. Appl. Microbiol.; 60: 21-30, doi: 10.1111/lam.12401, 2015.

[47] Kurekci C.; Padmanabha J.; Bishop-Hurley S.L.; Hassan E.; Al Jassim R.A.M.; McSweeney C.S.; "Antimicrobial activity of essential oils and five terpenoid compounds against Campylobacter jejuni in pure and mixed culture experiments", Int. J. Food Microbiol.; 166: 450-457, doi: 10.1016/j.ijfoodmicro. 2013.08.014, 2013.

[48] Chung P.Y.; Chung L.Y.; Navaratnam P.; "Potential targets by pentacyclic triterpenoids from Callicarpa farinose against methicillin-resistant and sensitive Staphylococcus aureus", Fitoterapia.; 94: 48-54, doi: 10.1016/j.fitote. 2014.01.026, 2014.

[49] Helander I.M.; Alakomi H.L.; Latva-Kala K.; MattilaSandholm T.; Pol I.; Smid E.J.; Gorris L.G.; Wright A.; "Characterization of the action of selected essential oil components on Gram-negative bacteria", Agric. Food Chem.; 46: 590-595, doi: 10.1021/jf980154m, 1998.

[50] Cowan, M.; "Plant products as antimicrobial agents", Clin. Microbial. Rev.; 12: 564-582, doi: 10.1128/CMR.12.4.564, 1999.

[51] Coppo, E.; and Marchese, A.; "Antibacterial activity of polyphenols", Curr. Pharm Biotechnol.; 15: 380390, doi: 10.2174/138920101504140825121142, 2014.

[52] Abbas, M.; Saeed, F.; Anjum, F. M.; Afzaal, M.; Tufail, T.; Bashir, M. S.; et al.; " Natural polyphenols: an overview", Int. J. Food Prop.; 20, 1689-1699, doi: 10.1080/10942912.2016.1220393, 2017.

[53] Sudhir, S. P.; Deshmukh, P.; and Verma, H. N. "Comparative study of antimicrobial effect of Nigella sativa seed extracts from different geographies", Int. J. Pharmacogn.; 3: 257-264, doi: 10.13040/IJPSR. 0975-8232.IJP.3(6).257-64, 2016.

[54] Nasser, M.; El-Mestrah, M.; As-sadi, F.; Cheaito, L.; Hijazi, A.; Chokr, A.; et al.; "Antibacterial, antioxidant and antiproliferative activities of the hydroalcoholic extract of the Lebanese Annona squamosa L. seeds", Int. Res. J. Pharm.; 8: 1-7, doi: 10.7897/2230-8407.08011, 2017.

[55] Selim, S.; El Alfy, S.; Al-Ruwaili, M.; Abdo, A.; and Al Jaouni, S.; "Susceptibility of imipenemresistant Pseudomonas aeruginosa to flavonoid glycosides of date palm (Phoenix dactylifera $\mathrm{L}$ ). tamar growing in Al Madinah, Saudi Arabia", Afr. J. Biotechnol.; 11: 416-422. doi: 10.5897/AJB11.1412, 2012.

[56] Al-Juraifani, A. A.; "Antimicrobial activity of some medicinal plants used in Saudi Arabia". Can. J. Pure Appl. Sci.; 5: 1509-1512, 2009.

[57] Malik, S. N.; "Antibacterial activity of olive (Olea europaea) leaves and arugula (Eruca sativa) seeds 


\section{Al-Nahrain Journal of Science}

ANJS, Vol.24 (4), December, 2021, pp. 59-67

extract", Int. J. Pharmacogn. Phytochem. Res.; 7: 307310, 2015.

[58] El Sayed, H. E. S. A.; and Aly, M. M.; "Antibacterial activities of six medicinal plants used traditionally by Saudi people to treat common diseases", $\mathrm{Br}$. Biotechnol. J.; 4: 499-510, doi: 10.9734/BBJ/2014/ 8532, 2014.

[59] Maqtari, Q. A. A.; and Al. Maqtari, M. A.; "In vitro antibacterial activity of different Yemeni leaves extracts of Lawsonia inermis against some bacterial pathogens", Int. J. Res. Stud. Biosci.; 2 (10): 52-7, 2014.

[60] Coppo, E.; and Marchese, A.; "Antibacterial activity of polyphenols" Curr. Pharm Biotechnol.; 15: 380390, doi: 10.2174/138920101504140825121142, 2014.

[61] Shohayeb, M.; Abdel-Hameed, E.; and Bazaid, S. "Antimicrobial activity of tannins and extracts of different parts of Conocarpus erectus L", Int. J. Pharm. Bio. Sci.; 3: 544-553, doi: 10.5829/idosi.wasj.2012.20.02.7156, 2013.

[62] Khayat, S.; Al-Zahrani, S. H.; Basudan, N.; AlZahrani, N. H.; and Subahi, J. A.; "Chemical composition and in vitro antibacterial activities of traditional medicinal plant: Olea sp." Biom. Res.; 29: 1037-1047, doi: 10.4066/biomedicalresearch. 29-173106, 2018.

[63] Daihan, S.; Al-Faham, M.; Al-shawi, N.; Almayman, R.; Brnawi, A.; zargar, S.; et al.; "Antibacterial activity and phytochemical screening of some medicinal plants commonly used in Saudi Arabia against selected pathogenic microorganisms", J. King Saud Univ. Sci.; 25: 115-120, doi: 10.1016/j.jksus.2012.11.003, 2013.

[64] Taguri T, Tanaka T, Kouno I.; "Antibacterial spectrum of plant polyphenols and extracts depending upon hydroxyphenyl structure", Biol Pharm Bull.; 29: 2226-35, 2006.

[65] Geissman T.; "Flavonoid compounds, tannins, lignins and related compounds. In: Florkin M, Stotz E, editors. Pyrrole Pigments, Isoprenoid Compounds and Phenolic Plant Constituents", 9, New York, Elsevier; p. 265, 1963.

[66] Mason T.; and Wasserman B.; "Inactivation of red beet betaglucan synthase by native and oxidized phenolic compounds", Phytochemistry.; 26: 2197202, 1987.

[67] Lim A.; Subhan N.; Jazayeri J. A.; John G.; Vanniasinkam T. and Obied H. K.; "Plant phenols as antibiotic boosters In vitro interaction of olive leaf phenols with ampicillin", Phytother Res.; 30: 503-9, 2016.

[68] Sarjit A.; Wang Y.; Dykes G. A.; "Antimicrobial activity of gallic acid against thermophilic Campylobacter is strain specific and associated with a loss of calcium ions", Food Microbiol.; 46: 227-33, 2015.
[69] Borges A.; Ferreira C.; Saavedra M. J.; Simões M.; "Antibacterial activity and mode of action of ferulic and gallic acids against pathogenic bacteria", Microb Drug Resist.; 19: 256-65, 2013.

[70] Wang S.S.; Wang D. M.; Pu W. J.; and Li D. W.; "Phytochemical profiles, antioxidant and antimicrobial activities of three Potentilla species", BMC Complement Altern Med.; 13: 321, 2013.

[71] Tomás-Menor L.; Barrajón-Catalán E.; SeguraCarretero A.; Martí N.; Saura D.; Menéndez J. A.; et al.; "The promiscuous and synergic molecular interaction of polyphenols in bactericidal activity: An opportunity to improve the performance of antibiotics", Phytother Res.; 29: 466-73, 2015.

[72] Soberón J. R.; Sgariglia M. A.; Dip Maderuelo M. R.; Andina M. L.; Sampietro D. A.; Vattuone M. A.; "Antibacterial activities of Ligaria cuneifolia and Jodina rhombifolia leaf extracts against phytopathogenic and clinical bacteria", J Biosci Bioeng.; 118: 599-605, 2014.

[73] Jiamboonsri P.; Pithayanukul P.; Bavovada R.; Chomnawang M.T.; "The inhibitory potential of Thai mango seed kernel extract against methicillinresistant Staphylococcus aureus", Molecules, 16, 6255-70, 2011.

[74] Rúa J.; Fernández-Álvarez L.; de Castro C.; Del Valle P.; de Arriaga D.; García-Armesto M. R.; "Antibacterial activity against foodborne Staphylococcus aureus and antioxidant capacity of various pure phenolic compounds", Foodborne Pathog Dis.; 8: 149-57, 2011.

[75] Mason, T. L.; and Wasserman, B. P.; "Inactivation of red beet beta-glucan synthase by native and oxidized phenolic compounds", Phytochemistry, 26: 21972202, doi: 10.1016/S0031-9422(00)84683-X, 1987.

[76] Scalbert, A.; "Antimicrobial properties of tannins", Phytochemistry, 30: 3875-3883, doi: 10.1016/00319422(91)83426-L, 1991.

[77] Chabot, S.; Bel-Rhlid, R.; Chenevert, R.; and Piche, Y.; "Hyphal growth promotion in vitro of the VA mycorrhizal fungus, Gigaspora margarita Beckerand Hall, by the activity of structurally specific flavonoid compounds under $\mathrm{CO} 2$-enriched conditions", New Phytol.; 122: 461-467, doi: 10.1111/j.14698137.1992.tb00074.x, 1992. 